\title{
Contribuições para uma reconstrução crítica da gramática moderna da maternidade
}

\author{
Marcelo Andrade Cattoni de Oliveira' \\ 0000-0002-2409-5804 \\ Stanley Souza Marques' \\ 0000-0001-5381-5615 \\ 'Universidade Federal de Minas Gerais, Belo Horizonte, MG, Brasil. 31270-901.
}

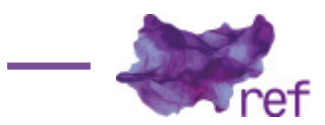

Resumo: O artigo é dividido em dois blocos. O primeiro deles reconstrói criticamente, ainda que de modo provisório e aberto, o núcleo duro da gramática moderna da maternidade, ou ainda, recupera a historicidade acumulada e dissimulada da maternidade, com suas tensões e contradições. No segundo bloco, a seu passo, propõe-se uma estratégia de aliança que leva a sério o direito fundamental à licença-paternidade. Uma estratégia de aliança desse tipo, enquanto prática político-constitucional ressignificante, explicita e intervém na historicidade constitutiva da maternidade e da paternidade. $E$, em última instância, desdobra o projeto constituinte de sociedade, subjacente à Constituição de 1988, porque resgata os potenciais democráticos imanentes à constitucionalização da licença-paternidade. Palavras-chave: Maternidades; paternidades; direito fundamental à licença-paternidade; estratégia de aliança.

Contributions to a Critical Reconstruction of The Modern Grammar of Motherhood Abstract: The article is divided into two parts. The first part critically reconstructs, although in a provisory and open way, the hard core of the modern grammar of motherhood, more particularly, recovers the accumulating and dissimulating historicity of motherhood, with its tensions and contradictions. The second block suggests a strategy of alliance that takes seriously the fundamental right to paternity leave. Such an alliance strategy, as a resignificant political-constitutional practice, makes explicit and intervenes in the constitutive historicity of motherhood and of fatherhood. And, ultimately, unfolds the constituent project of society, subjacent the Constitution of 1988, because takes back the democratic potentials immanent to the constitutionalization of paternity leave.

Keywords: Motherhood; Fatherhood; Fundamental right to fatherhood leave; Alliance Strategy.

\section{Considerações introdutórias}

Os passos dados adiante reconstroem criticamente, ainda que de modo provisório e aberto, a "historicidade acumulada e dissimulada" (Judith BUTLER, 2002) do núcleo duro da gramática moderna da maternidade; ou, ainda, recuperam os elementos-chave de modelos hegemônicos da maternidade na modernidade. Uma investida reconstrutiva desse tipo descortina a trajetória discursiva do "mito do amor materno" (cf. Elisabeth BADINTER, 1985), do "mito da mãe perfeita" (cf. Aminatta FORNA, 1999), da "rainha do lar" (cf. Margareth RAGO, 2014) ou, ainda, da "ideologia da maternidade intensificada" (cf. Sharon HAYS, 1998). Em outras palavras, um empreendimento crítico reconstrutivo desse tipo contextualiza a emergência de padrões da maternidade, comumente arredios à realidade da maioria das mulheres, explicita a historicidade e a pluralidade da maternidade e reconhece as tensões e as resistências imanentes ao processo complexo, polifônico, lento e contraditório, embora bem-sucedido, de sacralização da díade mãe-prole. 
E se essa "historicidade constitutiva" da maternidade por um lado precede e condiciona os discursos contemporâneos sobre maternidade (e paternidade), por outro frustra qualquer tentativa de controle da categoria maternidade dentro do discurso (BUTLER, 2002). Daí a reflexão e a proposição de uma estratégia de aliança (cf. Marco PRADO; Frederico COSTA, 2011; Raewyn CONNELL, 1995) que toma o direito fundamental à licença-paternidade como questão políticoconstitucional de primeira ordem. Uma estratégia de aliança desse tipo, enquanto prática políticoconstitucional ressignificante, denuncia e intervém na "historicidade acumulada e dissimulada" da maternidade e da paternidade. E, em última instância, desdobra o "projeto constituinte de sociedade", subjacente à Constituição de 1988, porque retoma e explora os potenciais democráticos abertos pela constitucionalização da licença-paternidade (cf. Marcelo CATTONI DE OLIVEIRA; Stanley MARQUES, 2018; 2017).

Com uma reconstrução crítica de modelos hegemônicos de maternidade, que mobiliza análises empíricas, sociológicas e históricas, recupera-se, em primeiro lugar, movimentos sóciohistóricos de implementação da ordem burguesa, de modernização e de higienização que remontam ao Brasil dos séculos XIX e XX. Recupera-se, aqui, algumas das articulações daquele cenário, como aquela que converte a criança em figura prestigiada no interior de um arranjo familiar específico, o modelo nuclear e conjugal, e a que sacraliza o instinto ou o amor materno, especificamente interpretado, naquela altura, como sentimento predeterminado, universal e necessário. Em segundo lugar, resgata experiências recorrentes naquele cenário, como o recurso a amas de leite e o abandono de crianças, que explicitam antes o caráter contingente e histórico dos sentimentos e das atitudes maternais. Em terceiro lugar, com Badinter (2011), diagnostica uma renovada veneração do instinto materno na contemporaneidade, cujos elementos se entrecruzam com os movimentos sócio-históricos acima aludidos. E, em quarto lugar, contribui para o debate sobre a historicidade da maternidade a partir de um ponto de vista específico, o do "projeto constituinte de sociedade", subjacente à Constituição de 1988, que tanto reproduz como desloca sentidos tradicionalmente atribuídos à maternidade e à paternidade. Mais especificamente, aposta-se em uma estratégia de aliança que leva a sério o direito fundamental à licençapaternidade. Amparado pelo debate teórico reconstruído ao longo do texto, pela revisão da literatura sobre maternidade na modernidade, no artigo se aposta em uma modalidade específica de luta política, a estratégia de aliança (cf. PRADO; COSTA, 2011 ; CONNELL, 1995), sobretudo, por três razões: essa variante da luta política, valendo-se da linguagem constitucional, (i) denuncia, desestabiliza e intervém em construções históricas que, em última instância, comprometem a autonomia das mulheres, dentro e fora de casa; (ii) sonda definições da paternidade comumente recalcadas porque associadas a uma feminilidade forjada; mais ainda, (iii) desdobra o projeto constituinte de sociedade, subjacente à Constituição de 1988, em alguns de seus aspectos mais centrais, como a igualdade, a liberdade, a maternidade e a paternidade.

\section{Desejo de filho ou dever de filho? O confinamento da mulher à maternidade}

Uma incursão pela Europa da segunda metade do século XVIII (Cf. BADINTER, 1985; FORNA, 1999; HAYS, 1998, Lurdes FIDALGO, 2003) e pelo Brasil dos séculos XIX e XX (cf. Jurandir COSTA, 2004; RAGO, 2014; Karoline CARULA, 2012; Maria Ângela D'INCAO, 2013; Maria Martha FREIRE, 2008; Ana Paula MARTINS, 2005; Maria Izilda MATOS, 2000; Rachel SOIHET, 2013; Cynthia TURACK, 2008; Ana Maria MAUAD, 2002; Joana PEDRO, 2013; Renata TOMAZ, 2015; Julita SCARANO, 2002) revela, guardadas as nuances próprias de cada cenário, um projeto audacioso de implementação da ordem burguesa; descortina movimentos de modernização e de higienização que reorganizaram radicalmente os arranjos familiares; situa a emergência de novas concepções da maternidade e da paternidade, agora orientadas em torno da criança de elite, por muito tempo conservada no anonimato.

No Brasil, o projeto de implementação do modelo burguês de família, elemento estruturante de um outro projeto, ainda mais ambicioso, de instauração da ordem burguesa, de modernização e higienização do país, esbarrava no antigo modo de viver colonial. Foi para destronar o patriarca colonial, redefinir as concepções da maternidade, da paternidade e da infância e reposicionar os membros familiares que, na virada do século XIX para o século XX, o "olhar médico [se articulou, não sem tensões, contradições e resistências] com a política intervencionista de um Estado planejador/reformador" (MATOS, 2000, p. 78).

Nesse cenário, atravessado por disputas com curandeiros, parteiras e homeopatas, o poder médico, em aliança com o poder estatal, pôde "expandir o controle sobre a família, normatiza[r] os corpos e os procedimentos, disciplina[r] a sociedade, ordena[r] o sexo e os prazeres" (MATOS, 2000, p. 79). O sucesso desse empreendimento é em parte explicado pela escolha estratégica de um de seus alvos de intervenção mais imediatos, as famílias abastadas, mais receptivas ao discurso médico, dadas suas pretensões de distinção de classe e raça, em uma época em que o isolamento 
feminino nas tarefas de esposa, mãe e dona de casa se convertia em valor cultivado por famílias de elite.

É nesse contexto de fins do século XIX e início do século XX que se preparou e articulou-se a tese de que o destino sociocultural da nação envolveria necessariamente o espaço privado do lar, cuja saúde e equilíbrio dependeriam particularmente da mulher, na posição de mãe devotada, e desde que ali confinada e servil às prescrições médicas. Não foram poucos os discursos científicos, filosóficos e populares que, em sintonia com aquela tese, creditavam às mulheres um relativo protagonismo, circunscrito às fronteiras estreitas do espaço doméstico; condicionavam o reconhecimento social da mulher e a possibilidade de ela ocupar uma posição de poder na dinâmica familiar à encarnação de modelos emergentes de boa mãe. Articulações históricas reveladoras, em última instância, do "papel que se espera[va] das mulheres na sociedade" (MARTINS, 2005, p. 1).

O discurso médico-higienista de fins do século XIX e início do século XX, então comprometido com os preceitos burgueses e com a retórica do amor, implementava "sua manobra mais ambiciosa e, talvez, mais bem-sucedida junto à família" à medida que convertia "quase completamente a figura sentimental do homem ao personagem do pai, e a da mulher ao personagem da mãe" (COSTA, 2004, p. 239). Para forjar essas personagens, centrais para a representação burguesa da família nuclear e, mais tarde, para o projeto modernizador republicano, a literatura médicohigienista deu cuidadosamente dois passos.

Enquanto o primeiro passo envolveu uma "tática separatista e singularizante" (COSTA, 2004, p. 235), que tomou "como objeto de aferição amorosa o homem e a mulher em situação préconjugal", o segundo passo procurou dar conta da distância construída entre a "natureza" dos homens e a das mulheres. Da fragilidade física delas, extraiu-se a sensibilidade, a delicadeza, a fragilidade moral e intelectual das mulheres, ao passo que da "força" e do "vigor" deles, deduziuse a superioridade moral e intelectual dos homens. Mas o discurso médico-estatal não só atestou, classificou, especificou e explorou as diferenças sexuais, como também apontou uma saída. 0 descompasso entre homens e mulheres poderia ser trabalhado e transposto exclusivamente na intimidade da vida conjugal fértil, fundada nas ideias de amor feminino e masculino, enfim congregadas num propósito maior, de natureza mais nobre: "[a] educação dos filhos começou, desta forma, a surgir como uma nova maneira de amar. O cuidado das crianças não era mais uma obrigação, mas um ato espontâneo de amor". Somente quando encarnados os modelos modernos de paternidade e de maternidade, forjados como "finalidade última" do homem e da mulher, seria possível transpassar a singularidade radical que separava homens e mulheres; "[s]ó este modo de amar conciliava o inconciliável" (COSTA, 2004, p. 238).

Aqui, dois movimentos se retroalimentavam: de um lado, despontava a estima social pela mulher-mãe, de outro, alargavam-se e complexificavam-se as exigências de cuidado da prole, indicativo de uma redefinição radical do status da criança. Paulatinamente deixava de ser suficiente alimentar, agasalhar e proporcionar algum conforto ao/à filho/a. Esse período assistia à imposição sobre a criança de uma infantilização que lhe era até então exterior, como demonstra uma "ampla literatura [que procurava] [...] dar conta da infância, explicar suas fases, entender suas necessidades e definir seus contornos; dizer o que é criança, como se caracteriza, como deve ser tratada e educada" (RAGO, 2014, p. 158). A emergência já no século XIX de sapatarias especializadas em calçados infantis, de casas de brinquedo, de livrarias onde se encontravam livros para crianças e de anúncios de médicos especializados em doenças infantis (MAUAD, 2002, p. 143-147) é sintomática das reviravoltas nas concepções da infância e da maternidade e de suas implicações mútuas a partir do final do século XIX.

Se por um lado a promoção médico-higienista da maternidade, de caráter polifônico, encobria, em última instância, a historicidade da maternidade, com suas tensões e contradições, por outro promovia um intenso debate sobre a maternidade, que invadia definitivamente a esfera pública. Em alguma medida e sobretudo para um grupo específico de mulheres, foi particularmente proveitoso o novo status atribuído à maternidade (cf. também FREIRE, 2008; TURACK, 2008). Para além da possibilidade de ocupar uma posição mais destacada na dinâmica familiar, muitas mulheres puderam se engajar em atividades acadêmicas e profissionais, ainda que, em geral, nas chamadas atividades femininas tradicionais.

\section{A mulher-mãe forjada pela imprensa: bela, recatada e do lar}

Publicações como A mãi de família, fundada pelo médico higienista Carlos Costa, são extraordinariamente ilustrativas do processo de construção da representação moderna da mulhermãe pelo poder médico. Sob inspiração do periódico francês La Jeune Mère, dirigido pelo também médico André Théodore Brochard, A mãi de família foi editado no Rio de Janeiro entre 1879 e 1888. Muito embora o jornal tenha dialogado mais imediatamente com mulheres brancas abastadas, já mães ou futuras mães, $A$ mãi de família também pretendia alcançar mulheres posicionadas em camadas menos privilegiadas, ainda que de modo indireto, pelo exemplo das mulheres de elite, 
seu alvo preferencial (cf. TURACK, 2008; CARULA, 2012). Mais tarde, na década de 1920, publicações como Vida Doméstica e Revista Feminina, em circulação no Rio de Janeiro, também refletiram, exploraram e modelaram o papel de mãe moderna (cf. FREIRE, 2008). O mesmo pode ser dito sobre jornais e revistas sulistas do final do século XIX e início do século XX, também particularmente afinados com a ideologia moderna da maternidade (cf. PEDRO, 2013). Em suas páginas, a maternidade se confundia com a própria identidade das mulheres. O Jornal do Comércio, de Desterro, antigo nome da capital de Santa Catarina, Blumenauer Zeitung, de Blumenau, Diário da Tarde, O olho da rua, Veritas, todos de Curitiba, Mercantil, Gazetinha e O Exemplo, de Porto Alegre, são algumas das publicações implicadas na promoção da função materna, então associada ao progresso e à civilização do país. O que foi dito até aqui deixa entrever um processo de construção da maternidade que mobiliza personagens específicos, como o especialista e a mídia: "[o]s processos de comunicação se tornavam cada vez mais importantes na transferência gradativa do aprendizado da maternagem - de um ambiente doméstico, familiar, tradicional e feminino para um ambiente público, midiático, científico e masculino" (TOMAZ, 2015, p. 158).

Se se dirige o olhar para algumas das publicações aludidas acima, todas elas influentes no final do século XIX e início do século XX,' emergem não só os contornos das novas representações da maternidade, mas, sobretudo, aquilo que pretendiam encobrir, a historicidade, a pluralidade e a artificialidade das concepções da maternidade, a fragilidade e as contradições da retórica do "instinto materno". Na medida em que as publicações suspendem a contingência e a plasticidade dos sentimentos e das atitudes maternais, a resistência e a desconfiança de muitas de suas interlocutoras, elas acabam por reconhecê-las; uma espécie de paradoxo, porque, escreve Butler (2003), "se alguém não quer reconhecer certas relações humanas como parte do humanamente reconhecível, logo, esse alguém já as reconheceu e busca negar aquilo que, de uma maneira ou de outra, já foi compreendido" (p. 236). Reconhecimento, continua ela, "se torna um esforço de negar o que existe e, assim, se torna um instrumento da recusa do reconhecimento". O cenário é de confronto entre as imagens da "boa mãe" e da "boa esposa", naturalizadas por periódicos da época, e o cotidiano da maioria das mulheres, das abastadas, cujas responsabilidades sociais e possibilidades de fruição do lazer se ampliavam com a urbanização efervescente e com a transferência do trabalho doméstico para outras mulheres, e das mulheres de camadas populares, que não tinham outra opção senão o trabalho fora de casa.

A emergência do modelo da mãe devotada colidiu com o alargamento do espaço público, provocado pela acelerada urbanização e pelo desenvolvimento comercial e industrial de algumas cidades brasileiras. O florescimento do espaço público tanto expandiu e complexificou as obrigações sociais creditadas às mulheres de elite como lhes possibilitou se libertar do confinamento doméstico, ainda que por breves momentos e em detrimento do trabalho de outras mulheres, muitas delas escravas, e sempre sob olhares vigilantes de familiares e autoridades. A cidade convidava as mulheres abastadas aos salões, concertos, bailes, às peças de teatro e cafeterias (TURACK, 2008; D'INCAO, 2013), enquanto interditava de forma mais ou menos violenta a livre circulação de homens e mulheres pobres em certos locais destinados e apossados pelas camadas mais elevadas da população (SOIHET, 2013). A saída delas, ricas e pobres, para o espaço público, não se deu sem impasses, tensões e ameaças. Para cada passo dado para fora do espaço privado do lar, "mais a sociedade burguesa lança[va] sobre seus ombros o anátema do pecado, o sentimento de culpa diante do abandono do lar, dos filhos carentes, do marido extenuado pelas longas horas de trabalho" (RAGO, 2014, p. 89).

Turack (2008) e Carula (2012) apontam o caráter pedagógico e normalizador dos discursos veiculados pelo jornal $A$ mãi de família, cuja autoridade remete à articulação de um conhecimento científico que toma a criança como marco referencial ou, mais precisamente, como objeto de cuidado das mães. Pressuposto o amor materno ou o instinto materno como fatalidade para todas as fêmeas, a vaidade, os divertimentos mundanos, a pobreza e a ignorância, sobretudo em relação aos preceitos médico-higienistas, apareciam como entraves ao cumprimento feminino dos sacrossantos desígnios da natureza. Na projeção da imagem da boa mãe pelo periódico, a amamentação, interpretada como prática natural do sexo feminino, foi peça-chave. Não sem evocar o amor materno dos insetos, dos cetáceos, das aves, das andorinhas e da víbora e não sem ameaçar suas leitoras com enfermidades de todo tipo. A mãi de família advertia: a boa ou a verdadeira mãe é aquela que amamenta os/as filhos/as. As mulheres que se ajustassem às minuciosas prescrições médicas, prometiam os/as articulistas, seriam contempladas com "uma relação mais sólida entre os membros da família, [com] o amor do marido" e se elevariam "à condição de figura central do seu território". Benesses para umas, ameaças para outras. Aquelas que confrontassem o destino traçado pela natureza, aquelas que relutassem ao enclausuramento

\footnotetext{
' A leitura de revistas se converteu em hábito de muitas mulheres e de muitos homens abastados inseridos no contexto urbano brasileiro. Apesar da pequena parcela de letrados/as e da pluralidade de práticas colidentes com os modelos de mulher e de maternidade despontantes naquela altura, final do século XIX e início do século XX, é certo que essas publicações contribuíram para uma atmosfera em geral mais propícia para os valores burgueses.
} 
do lar, que ousassem inadvertidamente atravessar a fronteira da anormalidade teriam necessariamente de lidar com o "sentimento de culpa, frustração, [com] os castigos da natureza contrariada, [com] os perigos físicos da não procriação ou da retenção do leite, no caso das mães etc." (RAGO, 2014, p. 109).

Em Vida Doméstica e Revista Feminina, Freire $(2008)$ identifica uma combinação estreita entre instinto materno, definidor da "essência feminina", patriotismo e racionalidade científica. Esse arranjo, em última instância, alarga e complexifica os significados da maternidade. À dimensão biológica foram sobrepostas dimensões científicas e públicas. Com um arranjo desse tipo, que mescla maternidade, função pública e racionalidade científica, argumentava-se que o instinto materno, por si só, era insuficiente. O exercício correto da maternagem seria mais exigente, bem diferente das antigas práticas maternas: a maternidade também não escapou à "classificação por oposição antigo/novo e tradicional/moderno - polarização usada desde o século XIX como recurso preferencial para explicar as transformações da sociedade brasileira" (FREIRE, 2008, p. 159). Sem jamais abandonar a ideia de instinto materno ou de essência feminina, esses periódicos também se comprometiam com a educação das mulheres, mas não com qualquer tipo de educação. Com a complexificação da administração da casa e do cuidado da prole, as mulheres deveriam se instruir e recorrer à orientação dos especialistas; "usar e fazer ciência [...] seria o novo papel social da mãe moderna" (FREIRE, 2008, p. 161). As prescrições médicas veiculadas pelas publicações não se furtavam a nenhum aspecto do universo doméstico moderno: "a localização, o mobiliário e a limpeza do dormitório infantil; o sono, o banho, o exercício e o vestuário"; os "parâmetros de normalidade de crescimento e desenvolvimento infantil"; a orientação de "condutas perante os principais problemas de saúde das crianças" (FREIRE, 2008, p. 163).

O jornal A mãi de família (cf. TURACK, 2008; CARULA, 2012), as revistas Vida Doméstica e Revista Feminina (Cf. FREIRE, 2008) e manuais sobre cuidado infantil publicados no século XX, a exemplo de Vamos criar seu filho e Cartilha às mães, escritos pelos médicos pediatras Carlos Prado e José Martinho da Rocha, respectivamente (cf. MARTINS, 2008), convergiam também numa estratégia discursiva particular: essas publicações tanto promoviam preceitos médicos, porque cientificamente embasados, como repudiavam as práticas da medicina popular e as mães que cediam a essas práticas. Repúdio correntemente acompanhado por ameaças às mães desobedientes. Ressaltavam as consequências nefastas senão fatais dessas práticas para as mães e sua prole. Por longo período, não só as mães, afáveis e carinhosas, embora ignorantes, mas também parteiras, curandeiras, criadas e parentes da família desafiaram o projeto médicohigienista em curso encarnado pelos homens da ciência.

\section{Confrontando o mito do instinto materno: amas de leite e abandono da prole}

Não foram poucas as crianças, muitas delas recém-nascidas, confiadas aos cuidados de amas de leite que se dividiam entre sua prole e outras crianças. Muitas dessas crianças foram criadas exclusivamente por amas de leite. Em certos casos, anos se passavam sem qualquer contato entre elas e seus progenitores, comportamento que não raras vezes se confundiu com a prática do abandono (BADINTER, 1985). A prática generalizada de despachar os/as filhos/as aos cuidados de amas de leite na Europa do século XVIII e no Brasil dos séculos XIX e XX, quer por necessidade econômica, quer para satisfazer a sociabilidade mundana tornada possível pela urbanização acelerada, também expõe o pouco prestígio senão a desconcertante irrelevância de que gozava a criança num contexto que ainda fabricava o mito do amor materno (BADINTER, 1985; COSTA, 2004). O aleitamento materno somente se converte em "problema nacional" com a reviravolta no status da criança ou, mais precisamente, com o reconhecimento da importância econômico-política da vida da criança de elite no Brasil do século XIX (COSTA, 2004, p. 256).

Que não se pense, no entanto, que naquela altura o instinto de sobrevivência fez calar o instinto materno. O envio dos/as filhos/as às amas de leite e o abandono de crianças, também corriqueiro à época, se se restringissem às camadas populares, alguns poderiam alegar, revelariam antes o predomínio do instinto de sobrevivência (FORNA, 1999, p. 43). A realidade, contudo, não cabe nesse argumento. As famílias abastadas também recorriam aos serviços de amas de leite, aliás, foram seus primeiros clientes, no distante século XIII, seguidas pela burguesia séculos mais tarde (BADINTER, 1985). No Brasil não foi diferente. Famílias afortunadas correntemente se socorriam às amas de leite, majoritariamente negras, mas também brancas, nacionais ou estrangeiras. Elas prestavam o seu serviço na casa dos patrões ou em suas próprias casas, onde também criavam as crianças. Princesas e príncipes imperiais também foram criados por amas, como pregava a tradição lusitana. Dom Pedro Il e sua irmã, a princesa Maria Paula, foram amamentados pela mesma ama, uma colona alemã (MAUAD, 2002, p. 161).

Foi na tentativa de lidar com a prática disseminada de se socorrer às amas de leite que o discurso higienista combinou a retórica do amor materno com a defesa da amamentação. $O$ 
constrangimento e a culpabilização das mães foram decisivos na construção e projeção da imagem da boa mãe. Em um passado mais distante, no Brasil Colônia, o aleitamento infantil por escravas foi prática comum e, mais tarde, os atrativos mundanos da emergente sociabilidade urbana colidiram com a também despontante defesa do aleitamento materno. Se o incremento de uma vida urbana atraiu também as mulheres para o espaço público, o discurso em favor do aleitamento materno, em direção contrária, pretendeu reconduzir as mulheres para o espaço privado do lar, domínio associado à satisfação das vocações e das competências forjadas como femininas (TURACK, 2008; CARULA, 2012; FREIRE, 2008; RAGO, 2014). Para enfrentar a recusa corrente da amamentação, então convertida em impasse nacional, o discurso médico-higienista apelou à natureza, duplamente infringida pela mãe que se negava a amamentar sua prole: "[e]m primeiro lugar, porque se conduzia de modo contrário a todas as fêmeas da classe dos mamíferos; em segundo lugar, porque contrariava sua outra vocação 'natural', a de ser mãe, conforme o figurino higienista" (COSTA, 2004, p. 256-257).

Ainda no Brasil, a prática do abandono, que variou ao longo do tempo, de cidade para cidade, e entre as áreas urbana e rural, foi encoberta por um silêncio socialmente compartilhado. Segundo Renato Pinto Venâncio (2013), "[a] sociedade acobertava o abandono, principalmente quando ele não adquiria feições selvagens, colocando em risco a vida do bebê. A ausência de processos, inquéritos, devassas e investigações detalhadas" (p. 194), prossegue ele, "implica[va] muitas vezes [...] multiplicação de enigmáticos silêncios" (p. 194). O autor ainda elenca alguns fatores que justificariam o abandono da prole pelas mães: (i) a condenação moral que pesaria sobre mulheres brancas bem posicionadas socialmente que assumissem filhos havidos fora do casamento, muito embora ele relativize essa motivação ao afirmar que "[o] mundo colonial conviveu com índices de $30 \%$ a $60 \%$ de bastardia entre os livres e de $50 \%$ a $100 \%$ entre os escravos", o que faria da mãe solteira ou concubina "um personagem aceito nas cidades e vilas do século XVIII" (VENÂNCIO, 2013, p. 199); (ii) a miséria de muitas mães e de muitos pais, agravada pelo nascimento de uma criança; (iii) causas fortuitas, como nascimento de gêmeos ou doença; (iv) a morte dos pais num período cravejado de altas taxas de mortalidade; ou, ainda, (v) forma de controle do tamanho das famílias.

Se, para Venâncio (2013, p. 202), a prática do abandono denota "uma forma paradoxal de se proteger a criança", um "verdadeiro gesto de ternura" das mães, muitas das reconstruções da prática do abandono, incluída, aqui, a de Venâncio (2013), parecem conduzir para um diagnóstico diferente, sobretudo se se considera que o fenômeno do abandono dos filhos "é tão antigo como a história da colonização brasileira" (Maria Luiza MARCILIO, 2006, p. 54). Em muitos casos, o abandono da prole não revelaria antes um desapreço social e um desinteresse dos pais? E mais, longe de revelar "um outro amor materno", como insinua o autor, o abandono de crianças não colocaria em xeque o amor materno enquanto categoria universal supostamente impressa pela natureza?

O abandono da prole e a recusa da amamentação anunciam antes a contingência do amor materno e do amor paterno, dão conta da variedade e da historicidade das atitudes de mães e pais, cujos laços com suas crianças foram também dificultados pelas altas taxas de mortalidade infantil. Memórias deixadas por muitos pais revelam muitas vezes pais brasileiros pouco consternados com filhos natimortos e pais conturbados com a morte de filhos que não sucumbiam nos primeiros anos de vida (MAUAD, 2002). As dramáticas taxas de mortalidade infantil contribuíram para que, naquela altura, as famílias admitissem, com alguma tranquilidade, a ideia de que uma nova criança substituiria aquela que havia falecido (SCARANO, 2002).

\section{A veneração renovada do instinto materno}

Vozes procedentes da ecologia, do feminismo diferencialista e das ciências do comportamento alinhadas com a etologia têm renovado, desde o final do século XX, velhos discursos naturalistas, mais precisamente, têm retonificado a retórica do instinto materno. $O$ diagnóstico de Badinter (2011), que abrange os Estados Unidos, o Canadá e a Europa, parece também alcançar a sociedade brasileira contemporânea, radicalmente distinta daquela onde se forjou os primórdios da noção de maternidade devotada. Mesmo em um cenário marcado pela postergação do casamento e da maternidade, pela queda nas taxas de fecundidade, pelo maior número de mulheres chefes de família, pela maior participação feminina na renda familiar, pelo aumento proporcional de divórcios, pela diversificação dos arranjos familiares, pelo relativo afrouxamento das hierarquias de gênero nas dinâmicas familiares, pela maior escolaridade feminina e pelo ingresso vertiginoso das mulheres no mercado de trabalho (cf. também OIT, 2016; Gary BARKER; Francisco AGUAYO, 2011), um conjunto de pesquisas brasileiras recentes, algumas delas reconstruídas a seguir, concorre para incluir o Brasil no retrato pintado por Badinter.

A ofensiva naturalista contemporânea, segundo Badinter (2011), encontra, mais uma vez, no instinto materno, a saída para muitos dos impasses sociais. Parece ilustrativo disso o movimento social pela humanização do parto e do nascimento no Brasil, em articulação no país pelo menos 
desde o final da década de 1980, segundo Carmen Susana Tornquist (2002). Em defesa da reconfiguração do modelo de atendimento ao parto hospitalar/medicalizado, o movimento ressignifica positivamente o corpo e visibiliza a experiência feminina do parto, não sem retomar a ideia de instinto materno: "ao apontar para um instinto e uma natureza (poderosa, positiva) das mulheres, sugerem uma essência feminina universal, liberada da dimensão simbólica, e, ainda, uma equivalência entre feminilidade e maternidade" (TORNQUIST, 2002, p. 490). Para parcela daqueles/as comprometidos/as com o movimento, especialistas e leigos/as, o protagonismo da técnica, da medicina e da cultura teria afastado as mulheres de sua própria natureza.

O aleitamento materno é outro elemento-chave do diagnóstico de Badinter. Seu ponto de referência não é outro senão um universo particular de mulheres, as heterossexuais, casadas e mães biológicas. Isso também é captado pela pesquisa de Dagmar Estermann Meyer (2000) sobre as representações de mãe reproduzidas pelo Programa Nacional de Incentivo ao Aleitamento Materno (PNIAM) nos anos 1980. A autora fala de uma nova politização da maternidade que, em parte, recupera e reconstrói velhos discursos médico-higienistas sobre maternidade e aleitamento materno. O Programa Nacional de Incentivo ao Aleitamento Materno, sintetiza Meyer (2000), é sintomático de "uma política estatal em favor da amamentação que busca, desde então, implantar, aperfeiçoar ou multiplicar estratégias que introjetam o aleitamento como comportamento social universal das mulheres" (p. 126).

Os elementos acima aludidos também aparecem na Campanha de Amamentação, segundo Eliane Cadoná e Marlene Neves Strey (2014). Para as autoras, a Campanha projeta a amamentação como prática materna intensiva, exclusiva e devotada ou, ainda, como prática natural, acessível a qualquer mulher disciplinada. A mãe que decididamente (e somente aquela que decididamente) se preocupa com o correto desenvolvimento físico, afetivo e cognitivo da criança e com o futuro da nação, amamenta: "[é] como se a mãe se doasse para a criança e desse a ela algo único, que o seu próprio corpo produz" (CADONÁ; STREY, 2014, p. 485). No pano de fundo, o velho conhecido instinto materno: "repete-se a ideia de que as crianças devem ser cuidadas por suas mães, dando a impressão de que estas necessitam ser suas mães biológicas, pois intimidade, afeto, comunicação e aquisição de confiança se expressam através do ato de amamentar ao peito" (CADONÁ; STREY, 2014, p. 485).

As autoras ainda inferem dos folders e cartazes elaborados para a divulgação da Campanha de Amamentação, no período de 1999 a 2010, entre outros aspectos, a tentativa de sensibilizar as mães e de responsabilizá-las pela amamentação, cuja prática é adequadamente aprendida se observada atentamente a técnica ensinada pela figura do especialista em saúde da criança, que assume posição destacada. A mãe, a seu passo, é posicionada como "sujeito de cuidado", sujeito passivo, "boa aprendiz da técnica a ela passada" (CADONÁ; STREY, 2014, p. 483-484). As práticas do cuidar e do nutrir se confundem, em última instância, com as práticas maternas: "[a]s mães são convidadas a salvar o futuro da nação, a deixar de lado seus empregos, negociar com sua chefia, readaptar sua rotina [...], mas cada vez menos se pergunta a elas o que pensam disso e como fazem para tornar essa realidade possível" (CADONÁ; STREY, 2014, p. 492). A paternidade, a seu passo, e não sem espanto, parece ter pouco que ver com a trama doméstica. O companheiro, quando muito, é posicionado como figura de apoio, assim como outros familiares, vizinhos e amigos.

O protagonismo do especialista e o apagamento da mãe como "sujeito singular na administração da própria vida, de sua doença ou de seu processo de tratamento" foram também observados por Solange Maria Sobottka Rolim de Moura e Maria de Fátima Araújo (2005) em pesquisa finalizada em 2003 sobre uma implementação do "Programa Mãe Canguru", que propõe que o bebê nascido prematuro e/ou de baixo peso seja acompanhado por um adulto que lhe proporcione contato pele a pele. As autoras descortinam a deflagração de uma hierarquia, não sem tensões e resistências, entre quem só diz e quem só ouve: o especialista e a mãe, respectivamente. E muito embora não fosse exigida pelo programa a participação da mãe do bebê, mas a de um "adulto", as autoras identificam que a figura da mãe é mais valorizada do que qualquer outra durante a internação do bebê, porque "[e]ntende-se que a proximidade da mãe favoreça a recuperação da criança, estimule o aleitamento materno e também o vínculo com o bebê" (MOURA; ARAÚJO, 2005, p. 39).

A pesquisa de Maria Simone Schwengber e Meyer (2011) também densifica a hipótese da veneração renovada do instinto materno ou da mitificação contemporânea da maternidade. Debruçadas sobre as edições da revista Pais \& Filhos, publicadas entre 1968 e 2005, as autoras concluem que a revista não só distingue duas posições, a da mulher e a da mulher gestante, como exalta a posição da mulher gestante. Essa conclusão se desdobra em algumas indagações: "[...] será mesmo que todas as mulheres acham maravilhoso fazer uma série de exames e passar pela inspeção de um grande número de profissionais da saúde periodicamente?". E mais, "[q]ue todas as mulheres acham maravilhoso viver, durante os nove meses da gestação, com um ser dentro do seu corpo, que depende inteiramente delas?" (SCHWENGBER; MEYER, 2011, p. 296). 
Segundo Schwengber e Meyer, os embaraços do processo gestacional aparecem timidamente aqui ou ali nos textos da publicação. E quando aparecem, são abordados paralelamente aos diferentes e acessíveis meios para contorná-los, para que possam as mulheres desfrutar dos (festejados) prazeres proporcionados pela gravidez. "A Pais \& Filhos incita-nos", escrevem elas, "a pensar em uma dupla e concomitante operação: uma que entroniza as mães em sua missão sagrada de gestar, e outra que ameaça as que fracassam na sua função de gerar filhos/as perfeitos/as e saudáveis" (SCHWENGBER; MEYER, 2011, p. 302).

Esse apanhado de pesquisas não só inclui o Brasil no diagnóstico de Badinter (2011), como também se desdobra noutra hipótese, a de que os diferentes modelos hegemônicos de maternidade que se sucederam e se sobrepuseram no curso da modernidade conservaram um núcleo duro. Todos eles pressupuseram a centralidade da criança, uma espécie de "império do bebê" (BADINTER, 2011 ), no interior de um arranjo familiar específico, o nuclear, monogâmico e heterossexual, onde se creditou preferencialmente senão exclusivamente às mães biológicas um pesado investimento físico, afetivo, cognitivo e monetário. Em outras palavras, esse núcleo duro remete a duas ideiaschave: (i) a de que a criança, porque "naturalmente" inocente, pura e dependente, requer cuidado especial e (ii) a de que o cuidado psicológico, social e intelectual da prole se confunde com o cuidado materno. Um arranjo desse tipo ecoa e se apoia sobre o instinto materno, do qual nenhuma mulher escaparia, salvo as "deficientes", "egoístas", "incompletas", todas elas invariavelmente censuradas porque "desviantes".

\section{Para além da gramática moderna da maternidade: masculinidades e paternidades hegemônicas}

Falar de masculinidade hegemônica significa falar daquela versão da masculinidade que ocupa, não sem disputa, tensão, contradição e resistência, a posição hegemônica no interior de uma ordem de gênero concreta e aberta a transformações históricas (CONNELL, 2005; CONNELL; James MESSERSCHMIDT, 2013). ${ }^{2}$ O conceito de masculinidade hegemônica leva a sério a historicidade do gênero, a pluralidade das masculinidades, a complexidade e a contradição das masculinidades, a agência dos sujeitos corporificados, a hierarquia entre masculinidades e a variedade de arenas onde se constroem masculinidades (CONNEL, 2005; CONNELL; MESSERSCHMIDT, 2013).

A versão hegemônica da masculinidade diz muito não apenas sobre as relações de dominação masculina, historicamente denunciadas pelos feminismos, mas também sobre as assimetrias específicas entre variantes da masculinidade. "Uma definição de macheza (hombría)", escreve Michael Kimmel (1997), "segue sendo a norma em relação à qual se medem e se avaliam outras formas de virilidade" (p. 50-51). Quer isso dizer que um processo implacável, orientado pelo repúdio de uma feminilidade forjada, atravessa a dinâmica das masculinidades (cf. KIMMEL, 1997; David GILMORE, 1994). Tornar-se um tipo específico de pai, o pai autoridade, o pai herói, o pai provedor, no interior de um modelo familiar também específico, o nuclear, monogâmico e heterossexual, comumente integra esse escrutínio infindável da performance dos homens aspirantes às credenciais da masculinidade hegemônica, com as vantagens simbólicas, sociais, culturais e materiais subjacentes, os "dividendos patriarcais", nos termos de Connell (2005).

A incitação corrente de distanciamento corporal e emocional que pesa sobre os homens, quer na relação com outros homens, quer na relação com a própria prole, é elucidativa de versões da masculinidade e da paternidade que se orientam "mais pelo que não se é, do que pelo que se é" e, quanto a este aspecto em particular, "sejam quais forem as variações de raça, classe, idade, etnia, ou orientação sexual, ser um homem [e um pai] significa não ser como as mulheres [e as mães]" (KIMMEL, 1997, p. 52), o que explica, em alguma medida, alguns dos impasses dos processos de construção de versões mais participativas, abrangentes ou mesmo democráticas da paternidade: "a noção de que é efeminado envolver-se nos cuidados da criança". Segundo Michael Lamb (1992), "é uma das mais cruciais barreiras atitudinais para o envolvimento paterno" (p. 29). Aqui, variantes da masculinidade e da paternidade aparecem como formas particulares "de representação e uso dos corpos dos homens" (CONNELL; MESSERSCHMIDT, 2013, p. 269) ou, em outras palavras, desenha-se uma articulação complexa entre processos de 'encorporação' da masculinidade hegemônica, a heterossexualidade e versões da paternidade.

Se se dirige o olhar para versões hegemônicas da paternidade e para as práticas paternas cotidianas, percebe-se a tensão, a ambiguidade, a contradição, a agência dos sujeitos e os dividendos patriarcais em jogo. Por um lado, um modelo específico de paternidade correntemente aparece como elemento ou característica associada à masculinidade hegemônica. Daí por que,

\footnotetext{
${ }^{2}$ Nascida no ano de 1944, em Sidney, como Robert William Connell, Raewyn Connell submeteu-se recentemente à cirurgia para mudança de sexo e nem todas as suas publicações foram ainda reeditadas com o seu nome social. Tendo isso em conta, embora nos refiramos à autora como Raewyn Connell no corpo do texto, optamos por conservar nas referências bibliográficas as assinaturas originais (ora Raewyn Connell, ora R. W. Connell, ora Robert Connell) da produção consultada.
} 
para muitos homens, tornar-se pai implica se aproximar da masculinidade hegemônica e, consequentemente, acessar as vantagens simbólicas, sociais, culturais e materiais correlatas. A própria constitucionalização da licença-paternidade revela as implicações mútuas entre masculinidade hegemônica, paternidade e prestígio social. A estima social de que goza o homempai-provedor e a atribuição do trabalho doméstico e de cuidado da prole à mulher, por sua vez, exemplificam algumas das vantagens usufruídas pelos homens que se tornam pais. A desresponsabilização corrente do pai em situações de abandono de crianças ${ }^{3}$ é particularmente ilustrativa dessas vantagens. Nesses casos, as expectativas sociais que pesam desproporcionalmente sobre as mulheres e as responsabilidades atribuídas às mães pelo cuidado da prole encobrem, em última instância, a figura paterna, como se o abandono de seu/sua filho/a não lhe dissesse respeito. Pesquisas que investigam o modo como a mídia reporta o abandono de crianças, como a de Auricéa Lima (2011), revelam a deserção da paternidade como dividendo patriarcal, como privilégio disponível aos homens em geral. Em poucas palavras, a responsabilidade é sempre e somente da mãe. Um dos casos de abandono reconstruídos por Lima (2011), desta vez ocorrido na Bahia, em junho de 2009, é extraordinariamente elucidativo disso:

[U]ma vizinha denunciou que a mãe de um bebê, com cinco dias de nascido, o teria jogado dentro de uma fossa. Ela morava com o marido, tinha outros cinco filhos e era lavradora. Quando os pais se apresentaram à delegacia, a mãe foi presa e o pai, que morava há dois anos com a companheira, negou saber que ela estava grávida e foi liberado. Na reportagem, a ausência da figura masculina que esperávamos surgir ao menos nos questionamentos é patente. É um silêncio que incomoda. Uma palavra não dita - pai (p. 40).

O que foi dito até aqui se desdobra, mais uma vez, noutra hipótese, a de que somente um arranjo institucional complexo, multifacetado e articulado poderá, a um só tempo, reconstruir concepções hegemônicas da maternidade e da paternidade e reorganizar as responsabilidades parentais. É no interior de um arranjo institucional desse tipo onde se projeta uma estratégia de aliança comprometida com o direito fundamental à licença-paternidade. ${ }^{4} \mathrm{E}$ isso porque a historicidade constitutiva da maternidade não só limita senão possibilita sua reelaboração discursiva. Ou ainda, se a maternidade (e a paternidade) significa(m) coisas diferentes, em diferentes épocas, para diferentes pessoas, é possível denunciar e intervir nessa história. Daí por que apostar em uma estratégia de aliança que leva a sério o direito fundamental à licençapaternidade. Uma estratégia político-constitucional desse tipo, como delineado a seguir, valendose da linguagem constitucional, pressupõe e explicita o caráter artificial, aberto e contingente da maternidade e da paternidade.

\section{Por uma estratégia de aliança que leve a sério o direito fundamental à licença-paternidade}

A Constituição da República de 1988 assegura licença de cento e vinte dias à gestante e atribui ao legislador infraconstitucional a tarefa de definir a extensão da licença-paternidade. Já o Ato das Disposições Constitucionais Transitórias fixa em cinco dias a duração da licençapaternidade, enquanto pendente regulamentação da matéria. Desse arranjo constitucional se abrem duas leituras que não só não se excluem mutuamente como se sobrepõem: se por um lado a Constituição retoma e encobre articulações históricas relativas à maternidade e à paternidade, por outro ela denuncia e tensiona a "historicidade constitutiva" (BUTLER, 2002) dessas categorias.

Os cento e vinte dias de licença-maternidade, se contrapostos aos cinco dias de licençapaternidade revelam, por um lado, a reprodução constitucional da distância historicamente forjada entre a maternidade e a paternidade. Em outras palavras, a história dessas categorias, porque precede e condiciona seus usos contemporâneos (BUTLER, 2002, p. 319), explica o enquadramento constitucional dissonante da maternidade e da paternidade. Essa mesma Constituição, por outro lado, reconhece pela primeira vez na história do constitucionalismo brasileiro a licençapaternidade como direito fundamental, o que também implica dizer que a Constituição desvia a trajetória discursiva da maternidade e da paternidade. Em outras palavras, os direitos fundamentais à licença-maternidade e à licença-paternidade ecoam os limites impressos e as possibilidades abertas pela "historicidade constitutiva" (BUTLER, 2002) da maternidade e da paternidade; atualizam e intervêm na "historicidade acumulada e dissimulada" (BUTLER, 2002) dessas categorias.

Aqui, a linguagem constitucional (já) denuncia aquilo que o núcleo duro da gramática moderna da maternidade dissimula: nem essência, nem destino, a maternidade moderna, aquela

\footnotetext{
${ }^{3}$ Aqui, falar de abandono de crianças significa falar do ato deliberado de deixar crianças em lugares, geralmente, públicos.

${ }^{4}$ Uma estratégia de aliança comprometida com o direito fundamental à licença-paternidade não esbarra ou rivaliza com demandas pela desprivatização do cuidado e da vida familiar, pelo contrário, podem ser combinadas, todas elas, por um arranjo institucional que, em diferentes frentes, opera contra a divisão sexual do trabalho, cerne da opressão e das desigualdades de gênero.
} 
que entrelaça instinto, devotamento e domesticidade, é uma fabricação. Deixa entrever que a maternidade e a paternidade são antes categorias vazias, "porque não têm nenhum significado último, transcendente", e transbordantes, "porque mesmo quanto parecem estar fixadas, ainda contêm dentro delas definições alternativas, negadas ou suprimidas" (Joan SCOTT, 1995, p. 93). Mais ainda, à medida que o projeto constituinte de sociedade, subjacente à Constituição de 1988 , irremediavelmente inconcluso, aberto à reconstrução da normatividade constitucional, aberto ao reconhecimento de novos sujeitos e de novos direitos, incorpora questões relativas à maternidade e à paternidade, entreabre-se à comunidade política um horizonte de reconstrução constitucional e democrática dessas categorias (cf. também CATTONI DE OLIVEIRA; MARQUES, 2018; CATTONI DE OLIVEIRA; MARQUES, 2017; CATTONI DE OLIVEIRA, 2017; Menelick de CARVALHO NETTO, 2003a; MARQUES, 2015).

A atuação organizada das mulheres no curso do processo constituinte de 1987-1988, inédita na história do constitucionalismo brasileiro, é particularmente elucidativa de uma Constituição que também desestabiliza significados historicamente atribuídos à maternidade e à paternidade. Estima-se que $80 \%$ das reivindicações do lobby do batom, como ficou conhecido o grupo de pressão das mulheres no curso do processo constituinte de 1987-1988, foram constitucionalizadas (Salete Maria da SILVA, 201 1, p. 269-270), incluindo aí o direito fundamental à licença-paternidade. A reinvenção constitucional da paternidade (e da maternidade) que emerge ali, na Assembleia Nacional Constituinte, está indissociavelmente ligada à articulação suprapartidária, horizontal e polifônica entre constituintes, feministas do Conselho Nacional dos Direitos da Mulher e militantes feministas (SILVA, 2011; CATTONI DE OLIVEIRA; MARQUES, 2018). O relato de Jacqueline Pitanguy (2011), que presidia naquela altura o Conselho Nacional dos Direitos da Mulher, é revelador disso: "[q]uando apresentamos a proposta de licença-paternidade, fomos duramente criticadas e até mesmo ridicularizadas por amplos setores do Congresso Nacional. "Argumentavam", continua ela, "que estaríamos incentivando a ausência dos homens do trabalho. Estávamos, no entanto, convencidas da relevância desta licença como um instrumento de mudança ideológica no papel dos homens frente à paternidade" (p. 25). Daí por que dizer que o direito fundamental à licença-paternidade, parte do legado da agência das mulheres naquele cenário, ecoa lutas por reconhecimento situadas no interior de um processo permanente mais amplo de aprendizagem coletiva, de conscientização política e social não imune a retrocessos.

O direito fundamental à igualdade entre homens e mulheres, os direitos fundamentais à licença-maternidade e à licença-paternidade e a corresponsabilização de mães e pais pela assistência, criação e educação dos filhos menores, longe de sanar a desigualdade de gênero, lança a igualdade, a maternidade e a paternidade como problemas político-constitucionais com os quais a comunidade política terá de lidar. Em outras palavras, a Constituição "nem dispensa, nem substitui a política" (CATTONI DE OLIVEIRA, 2016, p. 7011). Afastar-se dessa compreensão, depositando expectativas normativas que escapam à Constituição ou, em outras palavras, "absolutiza[r] o poder de regulamentação de condutas da Constituição e do Direito em geral" (CARVALHO NETTO, 1999) tem o seu preço: a "desestima constitucional" (CARVALHO NETTO, 2003b). O que foi dito até aqui situa e se desdobra na proposição de uma estratégia de aliança (cf. PRADO; COSTA, 2011; CONNELL, 1995) que leva a sério o direito fundamental à licença-paternidade.

Uma estratégia de aliança (cf. PRADO; COSTA, 2011 ; CONNELL, 1995) comprometida com o direito fundamental à licença-paternidade, enquanto eixo constitucional democrático de discussão e de proposição e cujos contornos serão esboçados a seguir, retoma e explora os potenciais democráticos abertos pela constitucionalização da licença-paternidade, sem perder de vista os seus limites imanentes. Mais especificamente, uma estratégia de aliança que leva a sério o direito fundamental à licença-paternidade (i) recorre à linguagem constitucional para afirmar e perturbar a "historicidade acumulada e dissimulada" da maternidade, que ainda credita preferencialmente senão exclusivamente às mães os encargos domésticos e de cuidado da prole; (ii) evoca a linguagem constitucional para sondar definições da paternidade comumente rejeitadas ou reprimidas; (iii) desdobra, em última instância, o "projeto constituinte de sociedade", subjacente à Constituição de 1988, porque desvenda e intervém na "historicidade constitutiva" de questões político-constitucionais (cf. também CATTONI DE OLIVEIRA; MARQUES, 2018; CATTONI DE OLIVEIRA, 2017). Em outras palavras, uma estratégia de aliança desse tipo reconhece e se apoia sobre 0 caráter insaturável dos direitos fundamentais, sem jamais perder de vista que "[...] em uma sociedade moderna, [...] que se pretende inclusiva e democrática", o seu "projeto interno de constituição exige de si mesmo, por meio da luta política e social, uma reconstrução e uma reinterpretação permanente do próprio sentido da igualdade e da liberdade" (CATTONI DE OLIVEIRA, 2017, p. 5455). E mais, (iv) uma estratégia de aliança compromissada com o direito fundamental à licençapaternidade também vai ao encontro das recomendações de dois relatórios recentes, $A$ Situação da Paternidade no Mundo (Ruti LEVTOV et al., 2015a; 2015b) e Masculinidades e Políticas de Equidade de Gênero: reflexões a partir da pesquisa IMAGES e uma revisão de políticas no Brasil, Chile e México (BARKER; AGUAYO, 2011). 
Prado e Costa (2011) retomam o conceito de "articulação" trabalhado por Ernesto Laclau e Chantal Mouffe (1985) para explorar as distinções e os potenciais de mudança social inscritos em duas modalidades de luta política, a estratégia de articulação e a estratégia de aliança. Diferentemente da estratégia de articulação, que constrói "um 'nós' (como na relação de equivalência) entre os diferentes sujeitos políticos" e desencadeia a "ressignificação da identidade de cada um desses sujeitos a partir da identificação de um elemento singular em torno do qual [...] [se estrutura] um projeto contra-hegemônico" (PRADO; COSTA, 201 1, p. 694), a estratégia de aliança constrói um outro tipo de vínculo entre os atores sociais; aqui, diferentes sujeitos políticos "se unem em torno de uma determinada reivindicação contrária a certa prática ou discurso específico da hegemonia [...] para fortalecer ações contra-ofensivas a essa prática ou discurso" (PRADO; COSTA, 2011 , p. 703).

Se diferentes movimentos sociais constroem diferentes vínculos estratégicos, seja para forjar "uma unidade simbólica, um 'nós' antagônico a um 'eles'” (PRADO; COSTA, 2011, p. 693), como propõe a estratégia de articulação, seja para "fortalecer bandeiras específicas presentes na relação entre eles" (PRADO; COSTA, 2011 , p. 694), como preconiza a estratégia de aliança, não parece nem adequado, nem proveitoso o menosprezo de antemão por qualquer das estratégias. Sobretudo se se reconhece que entre ambas as estratégias pode haver, inclusive, uma alimentação recíproca na construção da mudança social. É ilustrativa disso a possibilidade da estratégia de aliança se desdobrar em uma estratégia de articulação, (i) quer por oportunizar "o reconhecimento pelos diferentes sujeitos políticos de que enfrentam adversários semelhantes e que são os responsáveis pela impossibilidade de existência dos diferentes subcidadãos", (ii) quer por conferir "visibilidade e [...] legitimidade a pautas políticas muitas vezes invisibilizadas diante da dificuldade de alguns sujeitos políticos abrirem mão de suas bandeiras e da compreensão das mesmas como prioritárias", (iii) quer por "enfraquecer o processo de fragmentação dos movimentos sociais" (PRADO; COSTA, 2011 , p. 695).

Está em jogo, em última instância, tanto na estratégia de articulação como na estratégia de aliança, o desdobrar utópico de "um outro mundo possível", enquanto "horizonte que se constrói em termos das possibilidades oferecidas no presente, a fim de se lutar para a afirmação daquele horizonte como um futuro concreto" (PRADO; COSTA, 201 1, p. 694). De ambas as estratégias, entreabrem-se, ao menos, "fragmentos de justiça, aqui e agora", tomando de empréstimo as palavras de Connell (1995), que, a propósito, e como reconstruído mais adiante, defende uma "política de aliança" em termos muito próximos à estratégia de aliança de que falam Prado e Costa (2011).

A estratégia de aliança pode assumir pelo menos dois contornos possíveis. Em um deles, o vínculo construído entre diferentes movimentos sociais evoca um objeto já familiar. Aqui, o encadeamento entre movimentos sociais se dá "pela identificação de um traço compartilhado entre [...] [eles] [...], não havendo, nesse caso", escrevem os autores, "uma passagem da lógica da diferença para a lógica da equivalência, permanecendo a luta política no âmbito dos antagonismos democráticos" (PRADO; COSTA, 201 1, p. 703).

A estratégia de aliança também pode ganhar corpo quando movimentos sociais reconhecem novas bandeiras e optam estrategicamente por atuação política concertada. Muito embora a assimilação de novas demandas não promova necessariamente a redefinição da identidade dos movimentos sociais que se vinculam circunstancialmente, a estratégia de aliança prepara uma atmosfera mais ou menos favorável para a emergência de estratégias de articulação. Em uma estratégia de aliança desse tipo, movimentos sociais "que não apresentavam uma determinada pauta passam a incorporá-la em suas lutas, ao reconhecerem a legitimidade daquela reivindicação no processo de democratização social almejado, e a construir lutas conjuntas em torno daquela bandeira, sem que isso" ative necessariamente um "processo de ressignificação da identidade de cada um dos movimentos sociais que se aliaram pontualmente" (PRADO; COSTA, 2011 , p. 706).

A estratégia de aliança, tal como reconstruída até aqui, pode ser ainda alargada com propósitos democrático-constitucionais. Ela pode ser pensada como construção de vínculos não confinada à dinâmica dos movimentos sociais. A aliança pode também envolver grupos e organizações sociais. Um deslocamento desse tipo na concepção de estratégia de aliança se justifica, sobretudo, por duas razões: (i) uma estratégia de aliança comprometida com a reivindicação do direito fundamental à licença-paternidade deve também poder contar com o engajamento de homens heterossexuais que, (ii) enquanto grupo, não adotam a configuração de um movimento social.

Precisamente porque aos homens heterossexuais são creditados poder e privilégios, embora acessíveis e usufruídos de forma heterogênea na vida cotidiana (CONNELL, 2005) ou, ainda, precisamente porque lhes é ausente o peso do estigma e da opressão, parece difícil imaginá-los engajados num movimento social nos moldes dos movimentos feministas, negros, operários, gays ou dos direitos civis. Para Connell (1995), o interesse dos homens heterossexuais, embora em graus variados, pelas vantagens simbólicas, sociais, culturais e materiais disponíveis a eles em geral, ou 
seja, o interesse pelos "dividendos patriarcais" embaraça organizações de massa que incluam homens heterossexuais. Diante dessa impossibilidade constitutiva, como também mobilizar homens heterossexuais e contar com o seu engajamento em uma causa que também lhes diz respeito? Uma saída possível, com Connell (1995) e Prado e Costa (2011), é conceber a estratégia de aliança para além dos confins de atuação dos movimentos sociais. Vínculos pontuais e mais ou menos duradouros podem ser forjados entre movimentos sociais, grupos e organizações sociais. Uma diversidade de agentes, em diferentes arenas, a partir de distintos enfoques, em atuação político-estratégica concertada e mais ou menos duradoura, pode mobilizar o debate público sobre o direito fundamental à licença-paternidade e questões correlatas.

Se a maternidade absorvente é, em última instância, uma ficção reguladora, ela pode ser denunciada por uma estratégia de aliança que reconstrói criticamente compromissos constitucionais. Uma estratégia de aliança que reconhece o direito fundamental à licençapaternidade como objeto político-constitucional de primeira ordem parece poder forjar vínculos entre diferentes movimentos sociais, como os movimentos feministas, negros, LGBTI, dos trabalhadores, e grupos e organizações sociais, alguns deles mais imediatamente concebidos do que outros para tensionar concepções hegemônicas da feminilidade, da maternidade, da masculinidade e da paternidade.

Uma estratégia de aliança desse tipo pode desencadear a discussão político-constitucional de questões como (i) a prorrogação da licença-paternidade e da licença-maternidade em casos de nascimento ou adoção de filhos/as com enfermidades mais ou menos graves; (ii) a desprivatização do cuidado das crianças pelo incremento de infraestrutura pública e de serviços públicos de cuidado; (iii) a reconstrução da maternidade e da paternidade para além dos arranjos familiares nucleares e heterossexuais, das variáveis biológicas e dos laços consanguíneos e (iv) a desconstrução de compreensões correntes que posicionam os homens unilateralmente como obstáculos à reconfiguração constitucional e democrática da ordem de gênero. $O$ relatório Masculinidades e Políticas de Equidade de Gênero: reflexões a partir da pesquisa IMAGES e uma revisão de políticas no Brasil, Chile e México aponta um descompasso entre os estudos de homens e masculinidades e as políticas e as instituições públicas. Diferentemente dos estudos de homens e masculinidades, as políticas e as instituições públicas tendem a adotar uma perspectiva unilateral, que toma os homens como estorvos às transformações democráticas da ordem de gênero, jamais como parte da solução (BARKER; AGUAYO, 2011).

A licença-paternidade pode ativar vínculos tanto entre movimentos, grupos e organizações sociais que já atuam em torno das feminilidades, das maternidades, das masculinidades e das paternidades, como entre aqueles que até então não pautam essas categorias. Na medida em que movimentos sociais, grupos e organizações sociais absorvem a licença-paternidade como demanda política de primeira ordem, entreabre-se uma atmosfera mais favorável à construção de um projeto contra-hegemônico. E isso porque diferentes agentes políticos, comprometidos com uma pluralidade de pautas, podem se dar conta de que compartilham mais reivindicações do que julgavam num momento precedente à configuração da estratégia de aliança.

\section{Considerações finais}

A reconstrução de fragmentos da gramática moderna da maternidade fornece pistas das reviravoltas familiares dos últimos séculos. Acena para a emergência e a sobreposição de diferentes modelos hegemônicos de maternidade que conservam, contudo, um traço comum, um núcleo duro. A despeito da reconstrução e da sobreposição de padrões de maternidade e da reapropriação de seus elementos conforme os cenários, as personagens, os interesses e as relações de poder modeladoras de períodos particulares, subsiste uma ficção reguladora da maternidade que confunde cuidado da prole, cuidado materno e natureza.

A mesma história que limita os discursos contemporâneos sobre maternidade (e paternidade) se abre à reelaboração discursiva. Daí a aposta em uma modalidade específica de luta política que se vale da linguagem constitucional para desestabilizar construções históricas que, em última instância, comprometem a autonomia das mulheres, dentro e fora de casa. Uma estratégia de aliança que leva a sério o direito fundamental à licença-paternidade, como esboçado até aqui, ao deslocar significados hegemônicos da maternidade e da paternidade, dentro e a partir do discurso constitucional, pode fomentar, em alguma medida, a redistribuição dos encargos domésticos e de cuidado da prole que ainda pesam desproporcionalmente sobre as mulheres. Pode reconstruir maternidades e paternidades para além do arranjo nuclear, monogâmico e heterossexual e desconfiná-las de variáveis biológicas e laços consanguíneos. Pode ainda subverter compreensões que focalizam os homens exclusivamente como entraves, algumas vezes instransponíveis, à justiça de gênero. Uma estratégia de aliança desse tipo desdobra, em última instância, o Projeto Constituinte de 1988, que longe de sanar as controvérsias relativas à maternidade e à paternidade, as reconhece como questões constitucionais insaturáveis, o que implica dizer que a comunidade política terá de lidar com essas questões, embora jamais de modo definitivo. 


\section{Referências}

BARKER, Gary; AGUAYO, Francisco (Orgs.). Masculinidades y políticas de equidad de género: reflexiones a partir de la encuesta IMAGES: una revisión de políticas en Brasil, Chile y México. Rio de Janeiro: Promundo, 2011 . Disponível em https://promundo.org.br/recursos/masculinidades-ypoliticas-de-equidad-de-genero-reflexiones-a-partir-de-la-encuesta-images-y-una-revision-depoliticas-em-brasil-chile-y-mexico/?lang=castelhano. Acesso em 22/05/2019.

BADINTER, Elisabeth. O conflito: a mulher e a mãe. Rio de Janeiro: Record, 2011.

BADINTER, Elisabeth. Um amor conquistado: o mito do amor materno. Rio de Janeiro: Nova Fronteira, 1985.

BUTLER, Judith. Cuerpos que importan. Sobre los limites materiales y discursivos del "sexo". Buenos Aires: Paidós, 2002.

BUTLER, Judith. "O parentesco é sempre tido como heterossexual?". Cadernos Pagu, Campinas, n. 21 , p. 219-260, 2003. Disponível em http://www.scielo.br/scielo.php?script=sci_abstract\&pid=s01 04-83332003000200010\&Ing=pt\&nrm=iso\&tlng=pt. Acesso em 22/05/2019.

CADONÁ, Eliane; STREY, Marlene Neves. "A produção da maternidade nos discursos de incentivo à amamentação". Revista Estudos Feministas, Florianópolis, v. 22, n. 2, p. 477-499, maio/ago. 2014. Disponível em http://www.scielo.br/scielo.php?script=sci_abstract\&pid=S0104-026X2014000200 005\&lng =en\&nrm=iso\&tlng=pt. Acesso em 22/05/2019.

CARVALHO NETTO, Menelick de. "A hermenêutica constitucional e os desafios postos aos direitos fundamentais". In: SAMPAIO, José Adércio Leite (Org.). Jurisdição constitucional e direitos fundamentais. Belo Horizonte: Del Rey, 2003a. p. 141-163.

CARVALHO NETTO, Menelick de. "Racionalização do ordenamento jurídico e democracia". In: Assembleia Legislativa de Minas Gerais. A Consolidação das leis e o aperfeiçoamento da democracia. Belo Horizonte, 2003b. p. 13-38.

CARVALHO NETTO, Menelick de. "Requisitos pragmáticos da interpretação jurídica sob o paradigma do Estado Democrático de Direito". Revista Brasileira de Direito Comparado, Belo Horizonte, v. 3, p. 473-486, 1999.

CARULA, Karoline. "Perigosas amas de leite: aleitamento materno, ciência e escravidão em A Mãi de Família". História, Ciências, Saúde-Manguinhos, Rio de Janeiro, v. 19, p. 197-214, dez. 2012. Disponível em http://www.scielo.br/pdf/hcsm/v19s1/1 1.pdf. Acesso em 22/05/2019.

CATTONI DE OLIVEIRA, Marcelo Andrade; MARQUES, Stanley Souza. "Direito fundamental à licençapaternidade e masculinidades no Estado Democrático de Direito". Revista Culturas Jurídicas, Rio de Janeiro, v. 4, n. 9, p. 222-248, set./dez. 2017. Disponível em http://www.culturasjuridicas.uff.br/ index.php/rcj/article/view/364. Acesso em 22/05/2019.

CATTONI DE OLIVEIRA, Marcelo Andrade; MARQUES, Stanley Souza. "Paternidades e a identidade do sujeito constitucional no Brasil: um estudo a partir do direito fundamental à licença-paternidade". Revista da Faculdade de Direito UFPR, Curitiba, v. 63, n. 2, p. 9-38, ago. 2018. Disponível em https:/ /revistas.ufpr.br/direito/article/view/52320. Acesso em 22/05/2019.

CATTONI DE OLIVEIRA, Marcelo Andrade. Contribuições para uma Teoria Crítica da Constituição. Belo Horizonte: Arraes, 2017.

CATTONI DE OLIVEIRA, Marcelo Andrade. "Democracia constitucional: um paradoxo? Um diálogo, ainda que breve, com Luhmann, Habermas e Derrida". Empório do Direito, 2016. Disponível em https://emporiododireito.com.br/leitura/democracia-constitucional-um-paradoxo-um-dialogoainda-que-breve-com-luhmann-habermas-e-derrida-por-marcelo-andrade-cattoni-de-oliveira.

CONNELL, Robert W. Masculinities. Berkeley: University of California Press, 2005.

CONNELL, Robert W. "Políticas da masculinidade". Educação \& Realidade, Porto Alegre, v. 20, n. 2, p. 185-206, 1995. Disponível em https://seer.ufrgs.br/educacaoerealidade/article/view/71 725/40671. Acesso em 22/05/2019.

CONNELL, Robert W.; MESSERSCHMIDT, James W. "Masculinidade hegemônica: repensando o conceito". Revista Estudos Feministas, Florianópolis, v. 21 , n. 1, p. 241-282, jan./abr. 2013. Disponível 
em http://www.scielo.br/scielo.php?script=sci_arttext\&pid=S0104-026X2013000100014. Acesso em 22/05/2019.

COSTA, Jurandir Freire. Ordem médica e norma familiar. Rio de Janeiro: Graal, 2004.

D'INCAO, Maria Ângela. "Mulher e família burguesa". In: DEL PRIORE, Mary (Org.). História das mulheres no Brasil. São Paulo: Contexto, 2013. p. 223-240.

FIDALGO, Lurdes. (Re)construir a maternidade numa perspectiva discursiva. Lisboa: Instituto Piaget, 2003.

FORNA, Aminatta. Mãe de todos os mitos: como a sociedade modela e reprime as mães. Rio de Janeiro: Ediouro, 1999.

FREIRE, Maria Martha de Luna. "'Ser mãe é uma ciência': mulheres, médicos e a construção da maternidade científica na década de 1920". História, Ciências, Saúde-Manguinhos, Rio de Janeiro, v. 15, p. 153-171, jun. 2008. Disponível em http://www.scielo.br/scielo.php?pid=S0104-59702008 $000500008 \&$ script $=$ sci_abstract\&tIng $=$ pt. Acesso em 22/05/2019.

GILMORE, David D. Hacerse hombre. Concepciones culturales de la masculinidad. Traducción Patrik Ducher. Barcelona: Paidós, 1994.

HAYS, Sharon. As contradições culturais da maternidade. Rio de Janeiro: Gryphus, 1998.

KIMMEL, Michael S. "Homofobia, temor, vergüenza y silencio en la identidad masculina". In: VALDÉS, Teresa; OLAVARRÍA, José (Orgs.). Masculinidad/es: poder y crisis. Santiago: Isis Internacional, 1997. p. 49-62.

LACLAU, Ernesto; MOUFFE, Chantal. Hegemony and Socialist Strategy. Towards a radical democratic politics. London: Verso, 1985.

LAMB, Michael E. "O Papel do Pai em Mudança". Análise Psicológica, v. 1, n. X, p. 19-34, 1992.

LEVTOV, Ruti et al. A situação da paternidade e cuidado no Brasil. Washington: Promundo, Rutgers, Save the Children, Sonke Gender Justice, and the MenEngage Alliance, 2015a. Disponível em https://promundo.org.br/wp-content/uploads/sites/2/2016/10/relatorio_paternidade_03c_baixa.pdf. Acesso em 22/05/2019.

LEVTOV, Ruti et al. A situação da paternidade no mundo: resumo e recomendações. Washington: Promundo, Rutgers, Save the Children, Sonke Gender Justice, and the MenEngage Alliance, 2015b. Disponível em https://sowf.men-care.org/wp-content/uploads/sites/4/2015/07/State-of-the-WorldsFathers_Executive-Summary_Portuguese_web-1.pdf. Acesso em 22/05/2019.

LIMA, Auricéa Xavier de Souza. “'Mães más': um olhar sobre o abandono”. Gênero, Niterói, v. 11, n. 11 , p. 29-44, 2011.

MARCILIO, Maria Luiza. "A roda dos expostos e a criança abandonada na História do Brasil. 17261950". In: FREITAS, Marcos Cezar de. História social da infância no Brasil. São Paulo: Cortez, 2006. p. 53-80.

MARQUES, Stanley Souza. "Ampliar a licença-paternidade para despatriarcalizar o Estado e a sociedade". Gênero e Direito, João Pessoa, n. 1, p. 241-260, 2015. Disponível em http://www.periodicos. ufpb.br/ojs2/index.php/ged/article/view/24479. Acesso em 22/05/2019.

MARTINS, Ana Paula Vosne. "História da maternidade no Brasil: arquivos, fontes e possibilidades de análise". In: SIMPÓSIO NACIONAL DE HISTÓRIA, 23, 2005, Londrina, Associação Nacional de História. Anais do XXIII Simpósio Nacional de História - História: guerra e paz, 2005. p. 1-9.

MARTINS, Ana Paula Vosne. “'Vamos criar seu filho': os médicos puericultores e a pedagogia materna no século XX". História, Ciências, Saúde-Manguinhos, Rio de Janeiro, v. 15, n. 1, p. 135-154, jan./ mar. 2008. Disponível em http://www.scielo.br/scielo.php?pid=s0104-59702008000100008\&script =sci_abstract\&tIng=pt. Acesso em 22/05/2019.

MATOS, Maria Izilda Santos de. "Em nome do engrandecimento da nação: representações de gênero no discurso médico - São Paulo 1890-1930". Diálogos - Revista do Departamento de História da Universidade Estadual de Maringá, Maringá, v. 4, n. 4, p. 77-92, jan./abr. 2000. Disponível em http://ojs.uem.br/ojs/index.php/Dialogos/article/view/37603. Acesso em 22/05/2019. 
MAUAD, Ana Maria. "A vida das crianças de elite durante o Império". In: PRIORE, Mary Del. (Org.). História das Crianças no Brasil. São Paulo: Contexto, 2002. p. 137-176.

MEYER, Dagmar Estermann. "As mamas como constituintes da maternidade: uma história do passado?". Educação \& Realidade, Porto Alegre, v. 25, n. 2, p. $117-133,2000$. Disponível em https:/ /seer.ufrgs.br/educacaoerealidade/article/view/46838. Acesso em 22/05/2019.

MOURA, Solange Maria Sobottka Rolim de; ARAÚJO, Maria de Fátima. "Produção de sentidos sobre a maternidade: uma experiência no Programa Mãe Canguru". Psicologia em Estudo, v. 10, n. 1, p. 37-46, jan./abr. 2005. Disponível em http://www.scielo.br/pdf/pe/v10n1/v10n1 a05. Acesso em 22/ 05/2019.

OIT. Mulheres no trabalho. Tendências 2016. Genebra: OIT, 2016. Disponível em https://www.ilo.org/ wcmsp5/groups/public/—dgreports/—dcomm/_publ/documents/publication/wcms_457096.pdf. Acesso em 22/05/2019.

PEDRO, Joana Maria. "Mulheres do Sul”. In: DEL PRIORE, Mary (Org.). História das mulheres no Brasil. São Paulo: Contexto, 2013. p. 278-321.

PITANGUY, Jacqueline. "Mulheres, Constituinte e Constituição". In: ABREU, Maria Aparecida (Org.). Redistribuição, reconhecimento e representação: diálogos sobre igualdade de gênero. Brasília: IPEA, 2011. p. 17-45.

PRADO, Marco Aurélio Máximo; COSTA, Frederico Alves. "Estratégia de articulação e estratégia de aliança: possibilidades para a luta política". Revista Estado e Sociedade, Brasília, v. 26, n. 3, p. 685-716, set./dez. 2011 . Disponível em http://www.scielo.br/scielo.php?script=sci_arttext\&pid=SO 102-69922011000300013. Acesso em 22/05/2019.

RAGO, Margareth. Do cabaré ao lar: a utopia da cidade disciplinar e a resistência anarquista. Brasil 1890-1930. São Paulo: Paz e Terra, 2014.

SOIHET, Rachel. "Mulheres pobres e violência no Brasil urbano". In: DEL PRIORE, Mary (Org.). História das mulheres no Brasil. São Paulo: Editora Contexto, 2013. p. 362-400.

SCARANO, Julita. "Criança esquecida das Minas Gerais". In: DEL PRIORE, Mary (Org.). História das Crianças no Brasil. São Paulo: Contexto, 2002. p. 107-136.

SCHWENGBER, Maria Simone Vione; MEYER, Dagmar Estermann. "Discursos que (con)formam corpos grávidos: da medicina à educação física". Cadernos Pagu, Campinas, n. 36, p. 283-314, jan./ jun. 2011 . Disponível em http://www.scielo.br/scielo.php?pid=S0104-8333201 1000100011 \&script =sci_abstract\&tIng=pt. Acesso em 22/05/2019.

SCOTT, Joan Wallach. "Gênero: uma categoria útil de análise histórica". Educação \& Realidade, Porto Alegre, v. 20, n. 2, p. 71-99, jul./dez. 1995.

SILVA, Salete Maria da. A Carta que elas escreveram: A participação das mulheres no processo de elaboração da Constituição Federal de 1988. 201 1. Tese (Doutorado em Estudos Interdisciplinares sobre Mulheres, Gênero e Feminismo) - Programa de Pós-Graduação em Estudos Interdisciplinares sobre Mulheres, Gênero e Feminismo, Faculdade de Filosofia e Ciências Humanas da UFBA, Universidade Federal de Salvador, Salvador, BA, Brasil.

TOMAZ, Renata. "Feminismo, maternidade e mídia: relações historicamente estreitas em revisão". Galáxia, São Paulo, n. 29, p. 155-166, jun. 2015. Disponível em http://www.scielo.br/scielo.php?pid $=$ S1982-25532015000100155\&script=sciabstract\&tIng=pt. Acesso em 22/05/2019.

TORNQUIST, Carmen Susana. "Armadilhas da nova era: natureza e maternidade no ideário da humanização do parto". Revista Estudos Feministas, Florianópolis, v. 10, n. 2, p. 483-492, 2002. Disponível em http://www.scielo.br/pdf/ref/v10n2/14972. Acesso em 22/05/2019.

TURACK, Cynthia Fevereiro. Mulheres-mães: memória e construção de sentidos no discurso do periódico A Mai de Família (1879-1888). 2008. Dissertação (Mestrado em Memória Social) Programa de Pós-Graduação em Memória Social, Universidade Federal do Estado do Rio de Janeiro, Rio de Janeiro, RJ, Brasil.

VENÂNCIO, Renato Pinto. "Maternidade negada". In: DEL PRIORE, Mary (Org.). História das mulheres no Brasil. São Paulo: Contexto, 2013. p. 189-222. 
Marcelo Andrade Cattoni de Oliveira (mcattoni@direito.ufmg.br) é Professor Titular de Direito Constitucional do Departamento de Direito Público da Faculdade de Direito da Universidade Federal de Minas Gerais. Bolsista em Produtividade do CNPq (Pq 1D). Possui Mestrado (1997) e Doutorado (1999) em Direito pela Universidade Federal de Minas Gerais. Realizou Estágio de PósDoutorado como Bolsista CAPES em Teoria do Direito na Università degli Studi di Roma Tre (20082009).

Stanley Souza Marques (stanleymarques@ufmg.br) é doutorando, com bolsa CAPES, e mestre em Direito pela Universidade Federal de Minas Gerais (UFMG). Foi Professor Voluntário de Direito Constitucional I e Teoria do Estado II na Faculdade de Direito da UFMG (2016-2017).

\section{COMO CITAR ESSE ARTIGO DE ACORDO COM AS NORMAS DA REVISTA}

CATTONI DE OLIVEIRA, Marcelo Andrade; MARQUES, Stanley Souza. "Contribuições para uma reconstrução crítica da gramática moderna da maternidade". Revista Estudos Feministas, Florianópolis, v. 28, n. 2, e68037, 2020.

\section{CONTRIBUIÇÃO DE AUTORIA}

Marcelo Andrade Cattoni de Oliveira: concepção, análise de dados, elaboração do manuscrito, redação, discussão de resultados, revisão.

Stanley Souza Marques: concepção, análise de dados, elaboração do manuscrito, redação, discussão de resultados, revisão.

\section{FINANCIAMENTO}

O presente trabalho foi realizado com apoio da Coordenação de Aperfeiçoamento de Pessoal de Nível Superior - Brasil (CAPES) - Código de Financiamento 001 e do Conselho Nacional de Desenvolvimento Científico e Tecnológico (CNPq).

\section{CONSENTIMENTO DE USO DE IMAGEM}

Não se aplica.

\section{APROVAÇÃO DE COMITÊ DE ÉTICA EM PESQUISA}

Não se aplica.

\section{CONFLITO DE INTERESSES}

Não se aplica.

LICENÇA DE USO

Este artigo está licenciado sob a Licença Creative Commons CC-BY Internacional. Com essa licença você pode compartilhar, adaptar, criar para qualquer fim, desde que atribua a autoria da obra.

\section{HISTÓRICO}

Recebido em 16/10/2019

Aprovado em 22/10/2019 